\title{
Effects of Decompression Treatment for Controlling the Powderpost Beetle, Lyctus africanus Lesne, (Coleoptera: Lyctinae)
}

\author{
Kazushi Nakai ${ }^{1, *, \dagger}$, Tatsuya Hiraku ${ }^{1, \dagger}$, Izumi Fujimoto ${ }^{2, \dagger}$ and Tsuyoshi Yoshimura ${ }^{2,+}$ \\ 1 Production Engineering and Procurement Department, Yamaha Corporation, 283 Aoya-cho, Minami-ku, \\ Hamamatsu 435-8567, Japan; tatsuya.hiraku@music.yamaha.com \\ 2 Research Institute for Sustainable Humanosphere, Kyoto University, Uji Campus, Kyoto 611-0011, Japan; \\ izumi_fujimoto@rish.kyoto-u.ac.jp (I.F.); tsuyoshi@rish.kyoto-u.ac.jp (T.Y.) \\ * Correspondence: kazushi.nakai@music.yamaha.com; Tel.: +81-53-461-6114 \\ + These authors contributed equally to this work.
}

Academic Editor: Brian T. Forschler

Received: 8 May 2016; Accepted: 11 July 2016; Published: 15 July 2016

\begin{abstract}
The efficacy of decompression treatment as a non-destructive method to control larvae of the powderpost beetle, Lyctus africanus Lesne, was evaluated in the laboratory using various combinations of two pressure levels, $1.1 \mathrm{kPa}$ and $40 \mathrm{kPa}$, and three temperature levels, 20, 25, and $40{ }^{\circ} \mathrm{C}$. Larval mortality generally depended on weight reduction while decreases in the oxygen level had relatively little effect. The lower pressure, $1.1 \mathrm{kPa}$, significantly affected mortality, and no larvae survived after $12 \mathrm{~h}$ of this pressure treatment, at $25^{\circ} \mathrm{C}$. The average body weight was reduced with treatment time and temperature, and the reduction rate at $25^{\circ} \mathrm{C}$ was higher than that at the lower temperature, $20^{\circ} \mathrm{C}$. Effects on larvae of the higher pressure treatment, $40 \mathrm{kPa}$, with a $\mathrm{CO}_{2}$ gas purge, were tested to determine the feasibility of decompression treatment in the manufacturing process. Although higher pressure resulted in low mortality, the body weight was dramatically decreased using the $\mathrm{CO}_{2}$ purge. These results present important information on the possibility of using decompression treatment for wood products.
\end{abstract}

Keywords: decompression treatment; L. africanus; powderpost beetle; $\mathrm{CO}_{2}$ purge

\section{Introduction}

Both chemical and non-chemical treatments have been used to control pest insects in the manufacturing process for wood products such as musical instruments. Since many wood materials such as timber, laminated wood and plywood are processed and assembled to produce wood products, managing the pests in such raw materials is important for quality assurance in the final products.

Due to increasing public concern about environmental safety [1,2], non-chemical pest management has been extensively studied. Such methods have been used for pest management in museums, libraries and historic buildings because they convey a lower risk to materials and operators as well as the environment [3]. Inert gases such as carbon dioxide $\left(\mathrm{CO}_{2}\right)$ gas are often used in non-chemical/non-destructive methods due to the low risk of damage to materials. In order to utilize such treatments efficiently, the specific killing effect of these gases to all stages of the target insects living inside the wood material must be clarified. Kigawa et al. (2011) tested the effects of $\mathrm{CO}_{2}$ gas on some pest insects comparing it with the fumigation treatment by sulfuryl fluoride, and found that the mortality in painted timbers of the larvae of two species, Priobium cylindricum and Sitophilus zeamais, did not reach 100\% [4]. Applications of heat treatment including microwave irradiation have also been tested as alternatives [5-16]. In particular, short-term microwave exposure 
has been shown to produce higher mortality than topical insecticide applications and is comparable to fumigation while being less damaging than high-temperature treatments [5-16].

Lyctinae beetles are called "powderpost beetles" due to the way they expel wood frass when they emerge from infested wood materials. Lyctus brunneus (Stephens) has been studied extensively as one of the most important species of drywood pest insects $[17,18]$. The beetle larvae live inside the wood materials, spending several months to one year before emerging after becoming adults [19]. Therefore, the Lyctinae beetles in the materials are difficult to detect in early stages of infestation. Lyctus africanus Lesne is also an important species having very similar anatomical and ecological features to those of L. brunneus [18-20]. The two species have similar thermal tolerance [21]. In Japan, infestations of L. africanus have even become more common than those of L. brunneus, especially in the southern part of the main islands [22]; thus, L. africanus must be considered a key target when thinking about the development of a country-wide management system.

In general, the manufacturing of wood products such as musical instruments is comprised of four basic processes: drying, processing, painting, and assembling including adhesion. Wood products for musical instruments must maintain low moisture content to ensure the quality of the products, and it is well known that larvae of Lyctinae beetles need low-moisture-content wood for their survival, optimally conditioned at $16 \%$. The final target of the present study was to develop a novel insect management system adapted to the manufacturing process of wood musical instruments. The essential requirements we sought to fulfill were rapid treatment and high mortality without harming products or the environment.

For this purpose, fundamental data on decompression treatments applicable for the economically important powderpost beetle, L. africanus, are discussed together with the results regarding the effects of low-pressure treatment on another economically important species, L. brunneus.

\section{Materials and Methods}

\subsection{Insects}

This study utilized L. africanus larvae over $2 \mathrm{~mm}$ in length obtained from a laboratory colony maintained in the Deterioration Organisms Laboratory (DOL), Research Institute for Sustainable Humanosphere at Kyoto University for more than 20 years in a dark environmental chamber at $26{ }^{\circ} \mathrm{C}$ and $65 \%$ relative humidity (RH) [23]. For L. brunneus, larvae over $3 \mathrm{~mm}$ in length were also prepared from a laboratory colony which has been maintained in similar conditions to those of L. africanus.

\subsection{Weight Reduction Rate of Larvae}

The moisture contents of larvae of L. africanus were measured by kiln drying in order to obtain base data for the evaluation of moisture evaporation from the body. Closed Petri dishes with 10 larvae were dried in temperature-controlled chambers at four different temperatures, $25,40,60$ and $100{ }^{\circ} \mathrm{C}$. The change of weight was monitored after 1, 3, 5, 7 and $22 \mathrm{~h}$, and the weight reduction during a given time was calculated. The weight reduction rate, $W_{R}$, was calculated by the following Equation (1):

$$
W_{R}=\frac{W_{0}-W_{1}}{W_{0}} \times 100(\%)
$$

where $W_{0}$ is the total weight of 10 larvae before treatment, and $W_{1}$ is the total weight of 10 larvae after treatment. $W_{1}$ was measured $30 \mathrm{~min}$ afterincubation at room temperature and $45 \% \pm 5 \% \mathrm{RH}$.

\subsection{Experimental Apparatus and Decompression Treatment}

\subsubsection{Experimental Apparatus and Conditions}

A cylindrical acrylic chamber (320 mm diamater, $500 \mathrm{~mm}$ height) was used for decompression treatment. A closed glass Petri dish (75 mm diameter, $20 \mathrm{~mm}$ height) with 10 larvae was placed on 
the bottom of the chamber (Figure 1). In the decompression process, the pressure of the chamber was decreased by a vacuum pump (BSEW-150, Sato Vac Inc, Tokyo, Japan) at $20-25{ }^{\circ} \mathrm{C}$ and $45 \% \pm 5 \% \mathrm{RH}$. In this study, two levels of pressure, $1.1 \mathrm{kPa}$ or $40 \mathrm{kPa}$, were used. For the sake of convenience, $1.1 \mathrm{kPa}$ was regarded as the high vacuum condition (lower pressure), and $40 \mathrm{kPa}$ was defined as the low vacuum condition (higher pressure). The high vacuum condition $(1.1 \mathrm{kPa}$ ) was designed to determine the lethal conditions for the larvae of L. africanus, and the low vacuum condition was used to evaluate the feasibility of the decompression treatment in the manufacturing process.

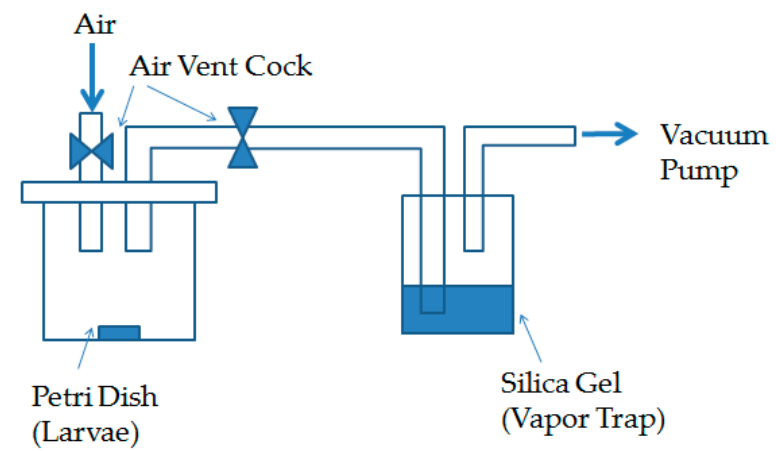

Figure 1. Experimental set-up for the high vacuum treatment $(1.1 \mathrm{kPa})$.

\subsubsection{Treatment in the High Vacuum Condition}

The pressure inside the acrylic chamber holding the test insects was kept at $1.1 \mathrm{kPa}$ for $16 \mathrm{~h}$ at three different temperatures, 20,25 and $40{ }^{\circ} \mathrm{C}$, in a temperature-controlled room. After the test period, the pressure was rapidly normalized with atmospheric pressure (approximately $100 \mathrm{kPa}$ ). In addition, other closed Petri dishes with test insects were kept in temperature-controlled chambers at three different temperatures, 20,25 and $40{ }^{\circ} \mathrm{C}$, under normal pressure as control samples.

\subsubsection{Treatment in the Low Vacuum Condition}

Figure 2 shows the experimental set-up for the low vacuum treatment. A $\mathrm{CO}_{2}$ bottle was connected to the acrylic chamber as with the high vacuum treatment in Figure 1. Two atmospheric conditions were used in this experiment: in the first, the chamber was vacuumed to $1.1 \mathrm{kPa}$, and then purged to $40 \mathrm{kPa}$ by $\mathrm{CO}_{2}$ (low vaccum $+\mathrm{CO}_{2}$ ); in the second, an air purge was substituted for $\mathrm{CO}_{2}$ (low vacuum + normal air). The chambers were then placed in a room at either $25^{\circ} \mathrm{C}$ or $40{ }^{\circ} \mathrm{C}$ for $48 \mathrm{~h}$. After the test period, the pressure was rapidly reduced to normal pressure as with the high vacuum treatment.

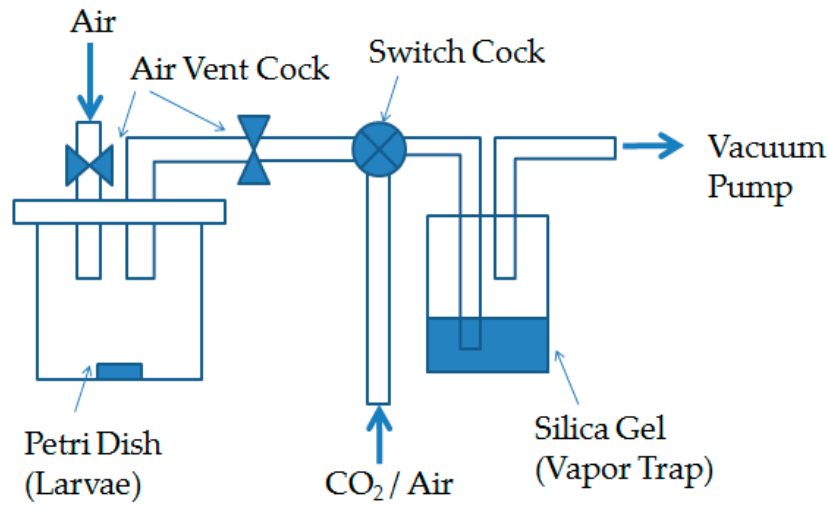

Figure 2. Experimental set-up for the low vacuum treatment under $\mathrm{CO}_{2}$ or air (40 kPa). 


\subsubsection{Evaluation of Effects of Decompression Treatments on L. africanus}

Effects of the decompression treatment were evaluated by both mortality and weight reduction rate, $W_{R}$, of larvae.

Mortality was calculated by measuring the number of surviving larvae after $16 \mathrm{~h}$ of post-incubation at $26^{\circ} \mathrm{C}, 65 \% \mathrm{RH} . \mathrm{W}_{R}$ was also calculated by Equation (1).

\subsection{Comparison of Effects of the High Vacuum Treatment on the Mortality of L. brunneus}

The larvae of the two species, L. africanus and L. brunneus, were prepared to compare the effects of the high vacuum treatment. Closed glass Petri dishes (75 mm diameter, $20 \mathrm{~mm}$ height) with 10 larvae were set-up with the same procedure as described in Section 2.3.1. They were exposed to a high vacuum condition (1.1 kPa) (Figure 1), and kept up to $4 \mathrm{~h}$ at $40^{\circ} \mathrm{C}$ in a temperature-controlled room. Pressure was rapidly returned to normal (approximately $100 \mathrm{kPa}$ ) after exposure.

Mortality and $W_{R}$ of larvae were calculated based on the procedure shown in Section 2.3.4.

\subsection{Statistical Analysis}

Both average mortality and $W_{R}$ were compared respectively by one-way analysis of variance (ANOVA) to analyze the effect of each treatment condition. The Tukey-Kramer test at 5\% critical difference was also used as a supplementary test.

\section{Results and Discussion}

\subsection{Moisture Reduction of Larvae by Heat Treatment}

Figure 3 shows the weight reduction rates of larvae of L. africanus at $25,40,60$ and $100{ }^{\circ} \mathrm{C}$ for 1,3 , 5,7 and $22 \mathrm{~h}$. The weight of larvae dramatically decreased to about $35 \%$ of the original weight after $1 \mathrm{~h}$ with complete mortality at $100{ }^{\circ} \mathrm{C}$. The shape of exposed larvae was significantly different from that of the unexposed larvae, and the color of skin became brownish.

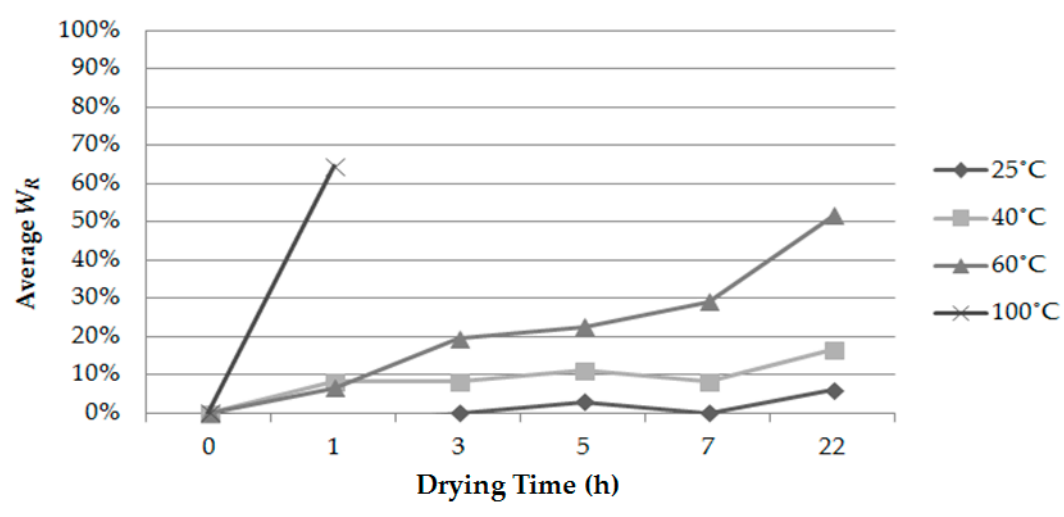

Figure 3. Average weight reduction rates of larvae of L. africanus after drying at $25,40,60$ and $100{ }^{\circ} \mathrm{C}$ for $1,3,5,7$ and $22 \mathrm{~h}(n=3)$.

In contrast, the weight reduction rates at both $40{ }^{\circ} \mathrm{C}$ and $60{ }^{\circ} \mathrm{C}$ for $1 \mathrm{~h}$ were only about $10 \%$. Treatment for over $5 \mathrm{~h}$ at $60{ }^{\circ} \mathrm{C}$ affected larvae mortality, and no larvae exposed for over $7 \mathrm{~h}$ could survive due to their $>30 \%$ body weight loss. Neither the $25^{\circ} \mathrm{C}$ nor $40{ }^{\circ} \mathrm{C}$ heat treatments affected the survival of larvae, and their weights varied less during the drying time. As a result, it was estimated that heat treatment below $40^{\circ} \mathrm{C}$ for $22 \mathrm{~h}$ under normal air pressure had no detrimental effect on the larvae of L. africanus. 


\subsection{Lethal Condition at High Vacuum Treatment}

Figure $4 \mathrm{a}$ shows average moltalities of the larvae after the decompression treatment at $1.1 \mathrm{kPa}$ under three different temperatures. All the larvae died after $12-\mathrm{h}$ and $16-\mathrm{h}$ treatments at $25{ }^{\circ} \mathrm{C}$. The larvae showed completely different shapes after treatment due to drastic water content reduction (Figure $4 \mathrm{~b}$ ). The body volume of the larvae increased when pressure was decreased to $1.1 \mathrm{kPa}$. Such volume increase was maintained during the treatment, and it decreased simultaneously with the increase of pressure after treatment. This result may suggest that a decompressed environment could remove air from the body water and promote vaporization.

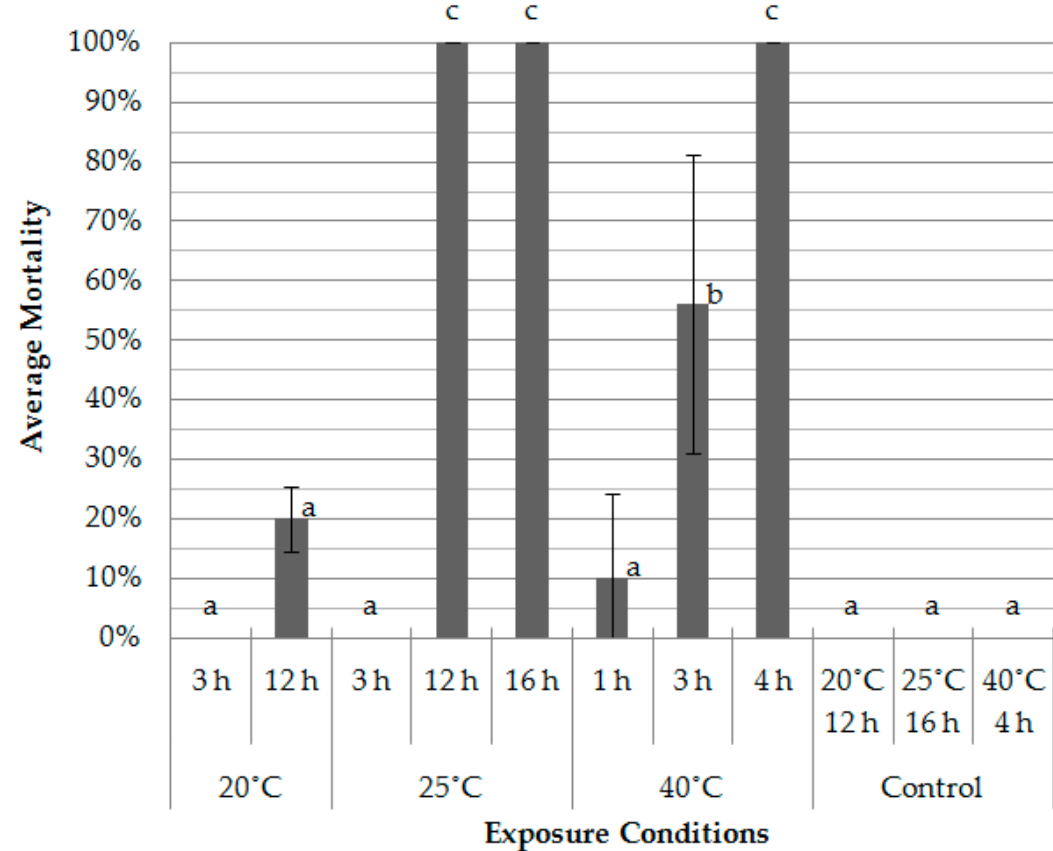

(a)
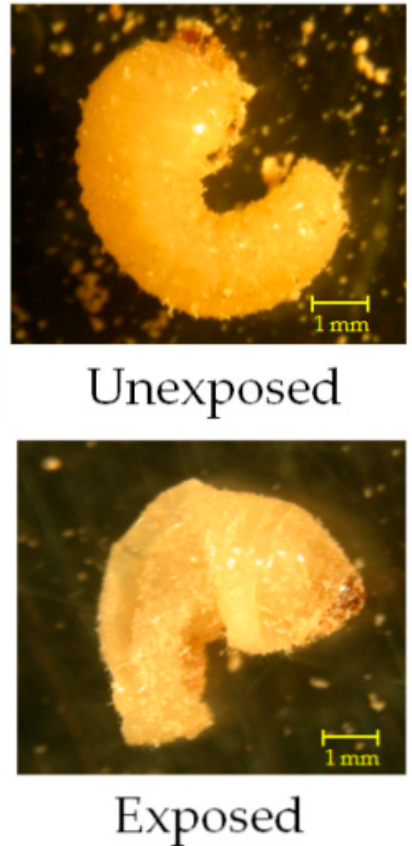

(b)

Figure 4. Mortality and the change of shape of L. africanus larvae by the high vacuum treatment $(n=5)$. (a) Mortality (mean $\pm \mathrm{SD}$ ) after decompression treatment at $1.1 \mathrm{kPa},(\mathbf{b})$ Photographs of larvae of L. africanus before (upper) and after treatment (bottom) at $25^{\circ} \mathrm{C}, 1.1 \mathrm{kPa}$ for $12 \mathrm{~h}$. For each condition, means with the same letters are not significantly different (Tukey-Kramer test; $p<0.05$ ) following one-way analysis of variance (ANOVA).

Mortality under $40{ }^{\circ} \mathrm{C}$ treatment significantly increased for the first $4 \mathrm{~h}$. In contrast, the treatment at $20{ }^{\circ} \mathrm{C}$ for $12 \mathrm{~h}$ resulted in only about $20 \%$ mortality, while the $25^{\circ} \mathrm{C}$ treatment showed $100 \%$ mortality after $12 \mathrm{~h}$. This phenomenon was probably due to the relationship between temperature and water vapour pressure; the longer exposure time will achieve higher mortality even at the $20{ }^{\circ} \mathrm{C}$ treatment. Furthermore, temperature apparently also contributed to the high mortality of insects. As a result, more than $12 \mathrm{~h}$ of the $25^{\circ} \mathrm{C}$ treatment or $4 \mathrm{~h}$ of the $40{ }^{\circ} \mathrm{C}$ treatment were considered to be lethal conditions for L. africanus larvae.

Table 1 shows the average weight reduction rates $\left(W_{R}\right)$ for 5 treatment conditions. The weight of larvae was decreased to approximately $50 \%$ of the original weight at one of the lethal conditions, $25{ }^{\circ} \mathrm{C}$ for $12 \mathrm{~h}$ (Figure $4 \mathrm{a}$, Table 1 ). Such reduction is equal to about $80 \%$ of their original water content, which was measured at about $65 \%$ by kiln drying at $100{ }^{\circ} \mathrm{C}$ for $1 \mathrm{~h}$ (Figure 3 ). Interestingly, higher mortality was obtained after $4 \mathrm{~h}$ of the $40{ }^{\circ} \mathrm{C}$ treatment, although $W_{R}$ was almost equal to that of the $12-\mathrm{h} 20^{\circ} \mathrm{C}$ treatment, which showed no effect on mortality (Figure $4 \mathrm{a}$ ). This probably is a result of the higher temperature as well as low pressure. 
Table 1. Average weight reduction rates $\left(W_{R}\right)(\%($ mean \pm SD) $)$ for the 5 treatments $(n=5)$.

\begin{tabular}{ccc}
\hline \multicolumn{2}{c}{ Treatment Condition } & \multirow{2}{*}{$\boldsymbol{W}_{\boldsymbol{R}}{ }^{*}$} \\
\cline { 1 - 2 } Temperature $\left({ }^{\circ} \mathbf{C}\right)$ & Time (h) & \\
\hline 20 & 12 & $40.74 \pm 6.13^{\mathrm{a}}$ \\
25 & 12 & $48.71 \pm 3.16^{\mathrm{a}}$ \\
40 & 1 & $1.31 \pm 6.01^{\mathrm{b}}$ \\
40 & 3 & $15.80 \pm 16.20^{\mathrm{bc}}$ \\
40 & 4 & $35.24 \pm 1.07^{\mathrm{ac}}$ \\
\hline
\end{tabular}

* Means with the same letter are not significantly different (Tukey-Kramer test; $p<0.05$ ) following one-way ANOVA.

Although the decrease in oxygen level was apparent under this pressure condition, such an effect is probably not a major reason for high mortality. Navarro and Calderon (1980) in their testing methods on three stored product insects (adults), reported that the exposure time became shorter with increased temperature, and the reduced treatment time may be due to a rise in temperature [20]. Therefore, the heating effect may be the major factor in killing the insects, and the $40{ }^{\circ} \mathrm{C}$ treatment is likely to have a serious effect on larvae mortality while dehydration can affect mortality at lower temperature.

\subsection{Effects of Low Vacuum Treatment}

Figure 5a,b show average mortality and $W_{R}$ of the larvae after exposure under $40 \mathrm{kPa}$ for 11 combinations of duration and temperature. As expected, both parameters were lower than those in the high vacuum treatments due to the relationship between air pressure and water vapour pressure. In general, the rate of water evaporation speeds up under the lower pressure conditions compared to normal pressure, because the environmental pressure becomes lower than the water vapour pressure. Therefore, the $40 \mathrm{kPa}$ treatment might be regarded as the unfavorable condition regarding the drying effect of decompression treatment.

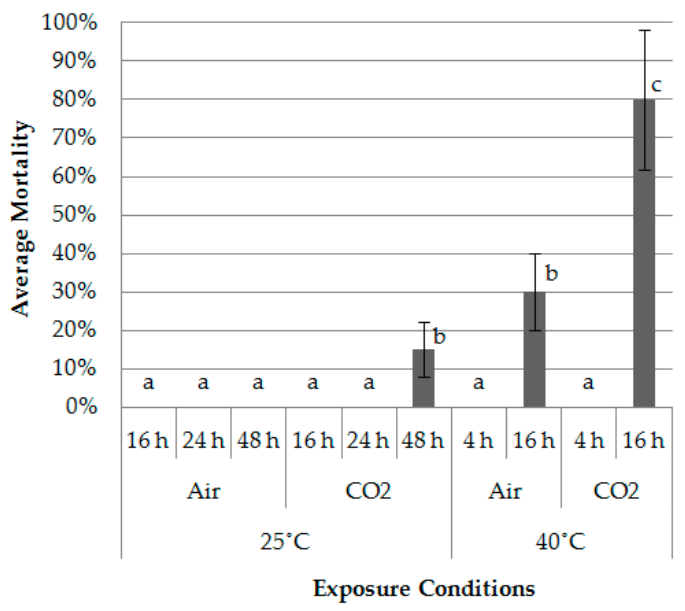

(a)

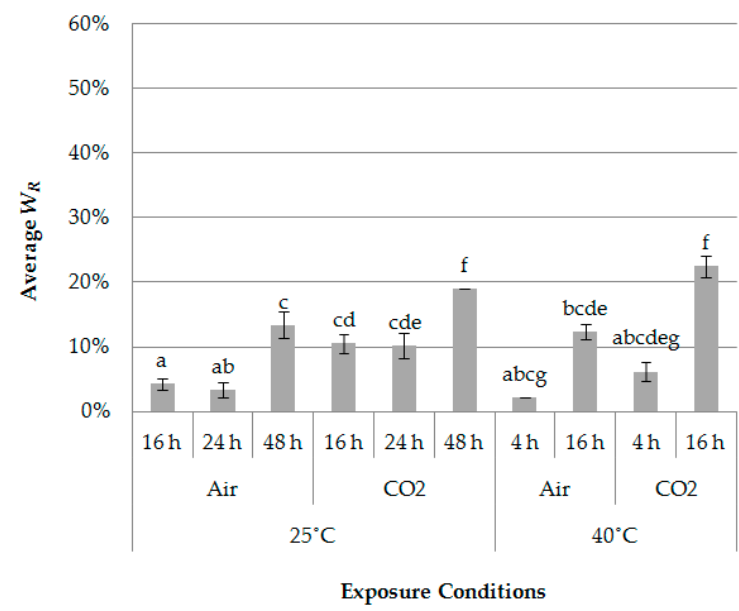

(b)

Figure 5. Average mortality and $W_{R}$ of larvae of L. africanus after the low vacuum treatment at $20-25{ }^{\circ} \mathrm{C}$ and $45 \% \pm 5 \%$ relative humidity $(\mathrm{RH})$ with air purge and $\mathrm{CO}_{2}$ purge $(n=5)$ : (a) Average mortality (mean $\pm \mathrm{SD}$ ) after low vacuum treatments $\left(40 \mathrm{kPa}\right.$ ) and purging; (b) Average $W_{R}$ (mean $\pm \mathrm{SD}$ ) after the low vacuum treatments $(40 \mathrm{kPa})$ and purging. For each condition, means followed by the same letter are not significantly different (Tukey-Kramer test; $p<0.05)$ following one-way ANOVA.

The average mortality among air-purged and $\mathrm{CO}_{2}$-purged treatments was significantly different $\left(25^{\circ} \mathrm{C}\right.$ for 48-h: $F=16.00, \mathrm{df}=1, p=0.0039 ; 40{ }^{\circ} \mathrm{C}$ for $\left.16-\mathrm{h}: F=77.93, \mathrm{df}=1, p=0.00031\right)$ (Figure $5 \mathrm{a}$ ). 
Treatments at $40{ }^{\circ} \mathrm{C}$ caused higher mortality than those at $25^{\circ} \mathrm{C}$, under the high vacuum condition $(1.1 \mathrm{kPa})$. In addition, the use of $\mathrm{CO}_{2}$ as a purging gas resulted in higher mortality and $W_{R}$ at both $25{ }^{\circ} \mathrm{C}$ and $40{ }^{\circ} \mathrm{C}$. As shown in Figure $5 \mathrm{~b}, W_{R}$ values with $\mathrm{CO}_{2}$ purging were 2 -fold greater compared to air purging. This may depend on the difference of relative humidity between containers in which the two gases were purged. The relative humidity in each chamber was controlled for air and $\mathrm{CO}_{2}$ purging. In this study, the original air was completely released in preparation for the high vacuum condition $(1.1 \mathrm{kPa})$. Each gas was purged after $1.1 \mathrm{kPa}$, obviously resulting in the different levels of relative humidity in each chamber. Air purging was introduced under laboratory room conditions $\left(20-25{ }^{\circ} \mathrm{C}, 45 \% \pm 5 \% \mathrm{RH}\right)$ in the chamber, while $\mathrm{CO}_{2}$ purging did not bring any moisture into the chamber. Finally, the relative humidity for $\mathrm{CO}_{2}$ purging was kept lower than that for air purging. The rate of water evaporation can increase at low relative humidity; thus, $\mathrm{CO}_{2}$ purging probably has an advantage for leading to higher mortality in the drying process. The role of relative humidity in some insects was studied by several reseachers, and it is suggested that lower humidity promoted the death of insects at the same gas composition [24,25].

$\mathrm{CO}_{2}$ gas itself can directly affect mortality, even if $W_{R}$ is lower than the lethal reduction rate. The effect of low oxygen or high $\mathrm{CO}_{2}$ concentrations on some insects have been previously investigated $[4,24,25]$. Banks (1978) suggested that oxygen concentrations below about $2 \%$ were needed for high mortality in stored product insects [26]. This suggests that the oxygen concentration might be an important factor for eradicating beetles in addition to the drying effect caused by a low pressure environment.

\subsection{Comparison of Effects of the High Vaccum Treatment against L. africanus and L. brunneus}

Table 2 shows average mortality and $W_{R}$ fin larvae of L. africanus and L. brunneus after high vacuum $(1.1 \mathrm{kPa})$ treatment at $40{ }^{\circ} \mathrm{C}$ for $4 \mathrm{~h}$. However, there were no significant differences in mortality or $W_{R}(F=1.30, \mathrm{df}=1, p=0.38)$ between the two Lyctinae species. These two species are morphologically quite similar [20]. From these results, it is possible that L. africanus and L. brunneus react similarly to environmental conditions close to the lethal level.

Table 2. Average mortality and $W_{R}$ of larvae of L. africunus and L. brunneus (\% (mean \pm SD)) after treatment at $40^{\circ} \mathrm{C}$ and $1.1 \mathrm{kPa}$ for $4 \mathrm{~h}(n=3)$.

\begin{tabular}{ccc}
\hline Species & Mortality & $\boldsymbol{W}_{\boldsymbol{R}}{ }^{*}$ \\
\hline Lyctus africanus & $100 \pm 0$ & $35.24 \pm 1.07^{\mathrm{a}}$ \\
Lyctus brunneus $^{\mathrm{a}}$ & $100 \pm 0$ & $36.17 \pm 0.42^{\mathrm{a}}$ \\
\hline
\end{tabular}

* Means followed by the same letter were not significantly different (Tukey-Kramer test; $p<0.05$ ) following one-way ANOVA.

Mortality of an insect depends on the tolerance of such external factors as thermal shock or air composition. Differences in lethal temperature for some closely related species have been studied [5,10,21], and L. africanus was reported to have similar thermal tolerance to that of L. brunneus [21]. Rust and Kennedy (1993) suggested that Lyctus spp. such as L. brunneus and L. linearis were similarly affected by environmental conditions [27]. According to such studies and the present results, it may be possible to apply the same lethal condition (temperature, pressure, and time) to all Lyctinae species.

\section{Conclusions}

In this study, the lethal conditions of decompression treatment with a specified pressure for larvae of $L$. africanus were analyzed, and the killing mechanism was also discussed. Decompression treatment with less than $40 \mathrm{kPa}$ could cause high mortality of larvae of Lyctus beetles. The lower pressure $(1.1 \mathrm{kPa})$ achieved complete mortality after $12 \mathrm{~h}$ at $25^{\circ} \mathrm{C}$ and $4 \mathrm{~h}$ at $40^{\circ} \mathrm{C}$, and the higher pressure $(40 \mathrm{kPa})$ with $\mathrm{CO}_{2}$ gas purging also resulted in high mortality after $16 \mathrm{~h}$ at $40^{\circ} \mathrm{C} . \mathrm{W}_{R}$ values for higher 
pressure with $\mathrm{CO}_{2}$ was estimated to be about twice that without $\mathrm{CO}_{2}$, and suggests that a dehydration effect on larvae was achieved with such a process.

Further research will be needed that tests the effectiveness and practicality of decompression treatments of larvae, and other live stages of the beetles such as eggs, adults and pupae in large and/or painted wood materials.

Acknowledgments: We thank Titik Kartika, Kyoko Inoue and Akio Adachi for their helpful assistance in preparing these experiments. This work was supported by JSPS KAKENHI Grant Number $15 \mathrm{H} 04528$.

Author Contributions: Kazushi Nakai, Tatsuya Hiraku and Tsuyoshi Yoshimura conceived and designed the experiments; Kazushi Nakai performed the experiments and analyzed the data; Tsuyoshi Yoshimura assisted in data collection; Izumi Fujimoto contributed to preparing insects; Kazushi Nakai wrote the paper.

Conflicts of Interest: The authors declare no conflict of interest.

\section{References}

1. Bennett, G.W.; Runstrom, E.S.; Wieland, J.A. Pesticide use in homes. Bull. Entomol. Soc. Am. 1983, 29, 31-40. [CrossRef]

2. Tsunoda, K. Improved management of termites to protect Japanese homes. In Proceedings of the 5th International Conference on Urban Pests, Singapore, 10-13 July 2005; pp. 10-13.

3. Querner, P. Insect pests and integrated pest management in museums, libraries and historic buildings. Insects 2015, 6, 595-607. [CrossRef] [PubMed]

4. Kigawa, R.; Komine, Y.; Torigoe, T.; Harada, M.; Imazu, S.; Honda, M.; Miura, S.; Kawanobe, W.; Ishizaki, T. Tests on insect eradication of wooden blocks damaged by wood-boring anobiids in historic buildings in Nikko. Sci. Conserv. 2011, 50, 141-155. (In Japanese)

5. Forbes, C.F.; Ebeling, W. Update: Use of heat for elimination of structural pests. IPM Pract. 1987, 9, 1-5.

6. Halverson, S.L.; Burkholder, W.E.; Bigelow, T.S.; Nordheim, E.V.; Misenheimer, M.E. High-power microwave radiation as an alternative insect control method for stored products. J. Econ. Entomol. 1996, 89, 1638-1648. [CrossRef]

7. Hurlock, E.T.; Llewelling, B.E.; Stables, L.M. Microwaves can kill insect pests. Food Manuf. 1979, $54,37$.

8. Lewis, V.R.; Haverty, M.I. Evaluation of six techniques for control of the western drywood termite (Isoptera: Kalotermitidae) in structures. J. Econ. Entomol. 1996, 89, 922-934. [CrossRef]

9. Lewis, V.R.; Power, A.B.; Haverty, M.I. Laboratory evaluation of microwaves for control of the western drywood termite. For. Prod. J. 2000, 50, 79-87.

10. Mahroof, R.; Subramanyam, B.; Throne, J.E.; Menon, A. Time-mortality relationships for Tribolium castaneum (Coleoptera: Tenebrionidae) life stages exposed to elevated temperatures. J. Econ. Entomol. 2003, 96, 1345-1351. [CrossRef] [PubMed]

11. Nakai, K.; Mitani, T.; Yoshimura, T.; Shinohara, N.; Tsunoda, K.; Imamura, Y. Microwave technology as a non-destructive termite control method-Preliminary results. In Proceedings of the 6th Pacific Rim Termites Research Group, Kyoto, Japan, 2-3 March 2009; pp. 36-40.

12. Nakai, K.; Mitani, T.; Yoshimura, T.; Shinohara, N.; Tsunoda, K.; Imamura, Y. Effects of microwave irradiation on the drywood termite Incisitermes minor Hagen. Jpn. J. Environ. Entomol. Zool. 2009, 20, 179-184.

13. Nelson, S.O. Possibilities for controlling stored-grain insects with RF energy. J. Microwave Power 1972, 7, 231-237.

14. Pinniger, D. Saving our treasures-Controlling museum pests with temperature extremes. Pestic. Outlook 2003, 14, 10-11. [CrossRef]

15. Shayesteh, N.; Barthakur, N.N. Mortality and behaviour of two stored-product insect species during microwave irradiation. J. Stored Prod. Res. 1996, 32, 239-246. [CrossRef]

16. Vadivambal, R.; Jayas, D.S.; White, N.D.G. Determination of mortality of different life stages of Tribolium castaneum (Coleoptera: Tenebrionidae) in stored barley using microwaves. J. Econ. Entomol. 2008, 101, 1011-1021. [CrossRef]

17. Beaver, R.A.; Sittichaya, W.; Liu, L.Y. A review of the powder-post beetles of thailand (Coleoptera: Bostrichidae). Trop. Nat. Hist. 2011, 11, 135-158. 
18. Peters, B.C.; Creffield, J.W.; Eldridge, R.H. Lyctine (Coleoptera: Bostrichidae) pests of timber in Australia: A literature review and susceptibility testing protocol. Aust. For. 2002, 65, 107-119. [CrossRef]

19. Gerberg, E.J. Lyctid powder post beetle second only to termite in wood damage. Pest Control 1957, 25, 37-38.

20. Gerberg, E.J. A Revision of the New World Species of Powder-Post Beetles Belonging to the Family Lyctidae; US Department of Agricluture: Washington, DC, USA, 1957.

21. Strang, T.J. A review of published temperatures for the control of pest insects in museums. Collect. Forum 1992, 8, 41-67.

22. Furukawa, N.; Yoshimura, T.; Imamura, Y. Survey of lyctine damages on houses in Japan: Identification of species and infested area. Wood Preserv. 2009, 35, 260-264. (In Japanese) [CrossRef]

23. Antrim, R.L.; Chan, Y.C.; Crary, J.R., Jr.; Harris, D.W. Method for Obtaining a Purified Cellulose Product from Corn Hulls. U.S. Patent No. 4239906, 16 December 1980.

24. Navarro, S.; Calderon, M. Integrated approach to the use of controlled atmospheres for insect control in grain storage. In Controlled Atmosphere Storage of Grains; Elsevier Scientific Publishing Company: Amsterdam, The Netherlands, 1980; pp. 73-79.

25. Kigawa, R.; Yamano, K.; Miura, S.; Maekawa, S. An automated anoxic treatment chamber for cultural objects: A novel system with nitrogen generator. Sci. Conserv. 1999, 38, 1-8. (In Japanese)

26. Banks, H.J. Recent Advances in the Use of Modified Atmospheres for Stored Product Pest Control. Available online: http://spiru.cgahr.ksu.edu/proj/iwcspp/pdf2/2/198.pdf (accessed on 14 January 2016).

27. Rust, M.K.; Kennedy, J.M. The Feasibility of Using Modified Atmospheres to Control Insect Pests in Museums; Getty Publications: Los Angeles, CA, USA, 1993; pp. 104-121.

(C) 2016 by the authors; licensee MDPI, Basel, Switzerland. This article is an open access article distributed under the terms and conditions of the Creative Commons Attribution (CC-BY) license (http:/ / creativecommons.org/licenses/by/4.0/). 